\title{
BMJ Open Mapping the digital food environment: a scoping review protocol
}

\author{
Sabrina Ionata Granheim (D) , ${ }^{1}$ Elin Opheim, ${ }^{2}$ Laura Terragni, ${ }^{3}$ Liv Elin Torheim, ${ }^{3}$ \\ Miranda Thurston ${ }^{1}$
}

To cite: Granheim Sl, Opheim E, Terragni L, et al. Mapping the digital food environment: a scoping review protocol. BMJ Open 2020;10:e036241. doi:10.1136/ bmjopen-2019-036241

- Prepublication history for this paper is available online. To view these files, please visit the journal online (http://dx.doi. org/10.1136/bmjopen-2019036241).

Received 06 December 2019 Revised 27 February 2020 Accepted 06 April 2020

Check for updates

(C) Author(s) (or their employer(s)) 2020. Re-use permitted under CC BY-NC. No commercial re-use. See rights and permissions. Published by BMJ.

${ }^{1}$ Department of Public Health and Sport Sciences, Inland Norway University of Applied Sciences, Elverum, Norway

${ }^{2}$ Department of Research,

University Library, Inland Norway University of Applied Sciences,

Elverum, Norway

${ }^{3}$ Department of Nursing and Health Promotion, OsloMet Oslo Metropolitan University, Oslo, Norway

Correspondence to

Sabrina Ionata Granheim; sabrina.granheim@inn.no

\section{ABSTRACT}

Introduction Food environments are the interface through which people interact with the broader food system. They are a key determinant of healthy and sustainable diets. The widespread use of digital technology in late modernity and the shift towards a digital society have posed new challenges for nutrition and health, with a concomitant surge in research on social media, digital health promotion interventions, and more recently, increasing interest in digital food marketing. While the literature is abundant on studies linking food, nutrition and digital technology, the effort to conceptualise and describe the digital food environment is new. This scoping review aims to support the development of a definition of the digital food environment and characterise it, along with key thematic research trends on this topic and potential consequences for nutrition and health.

Methods and analysis The planned scoping review will be supported by the methodological framework proposed by Arksey and 0'Malley and further developed by Levac et al. Development and reporting will follow the Preferred Reporting Items for Systematic Reviews and MetaAnalyses-Extension for Scoping Reviews (PRISMA$\mathrm{ScR}$ ) checklist and guidelines. The development of the search strategy was guided by the food environment conceptual framework developed by Turner et al. Four databases will be searched: MEDLINE, EMBASE, Scopus and Web of Science. Citation searching will be applied to identify additional studies, through checking of reference lists of primary studies and reviews. Studies in English, published from the year 2000 onwards, will be included. No geographical or population limits will be applied. Data will be extracted and analysed using a standardised charting tool.

Ethics and dissemination No ethical approval is required for this study. The results will be submitted to an international peer-reviewed journal and scientific conferences. They will be disseminated through digital science communication platforms, including academic social media, to amplify its reach and usefulness.

\section{INTRODUCTION}

Food environments have been defined in several ways, ${ }^{1-4}$ more recently and concisely as the interface through which people interact with the broader food system. ${ }^{5}$ The role of food environments in the current multiple burden of malnutrition (undernutrition, overweight, obesity and micronutrient deficiencies) and
Strengths and limitations of this study

The proposed scoping review will map the existing research on food environments and digital technology, contributing to the theoretical development of the concept of digital food environment and its potential consequences for nutrition and health.

- By focusing on the breadth of the research landscape over depth, it will allow for the description of research trends and main themes investigated in the literature, and the identification of research gaps for future investigation.

- Although comprehensive, the study design for this proposed scoping review has limitations regarding the number of databases, the language and search terms used, and may under-represent research from low-income and middle-income countries.

- By focusing on food environments, the study may not capture the whole extent of research being conducted on the linkages between food, nutrition and digital technology.

diet-related non-communicable diseases is widely recognised. ${ }^{6}$ They are a key determinant of healthy and sustainable diets.

The number of published research articles assessing the food environment has increased considerably in the past decade. ${ }^{7}$ A number of systematic reviews on food environments and the link with nutrition and health outcomes have been conducted..$^{8-11}$ Some systematic reviews focus on particular aspects of the food environment, such as food marketing, ${ }^{12}$ rather than on the food environment as a whole. While research gaps and challenges still exist in food environment research, for example, challenges on standardised measurement tools and methods, an important topic has recently emerged, related to the role of digital technology for nutrition and health.

Digital technology contributes to framing the social world and thus influencing how people understand and experience it. At the same time, people individually and collectively create the digital world through complex multidirectional processes. This is 
Table 1 Scoping review questions

\begin{tabular}{ll}
\hline Aspect & Research questions \\
Descriptive & What is the volume of studies published by year? \\
Wethods & What is the geographical scope of the publications? \\
What types of studies are published? \\
What population groups are being studied? \\
Wutrition and health & What themes are being studied? \\
& What dimensions* of food environments are being studied? \\
& That extent are studies measuring outcomes in nutrition and health? \\
& What are the outcomes in health and nutrition reported to date, if any?
\end{tabular}

${ }^{*}$ Availability, prices, vendor and product properties, marketing, accessibility, affordability, convenience and desirability. The dimensions are defined by the conceptual framework applied in the study.

particularly relevant given the growth and popularisation of social media in recent years, which relies on this individual-technology dynamic interaction, and has provided millions with the opportunity to create content on food and nutrition and share it online. ${ }^{13}$

Social media has been the topic of several health-related systematic reviews to date. In fact, health represents a major share of research within the broader field of social media research. ${ }^{14}$ A systematic review and meta-analysis of randomised controlled trials by Williams et $a l^{15}$ explored the use of social media to promote physical activity and healthy diets for the general population. Maher et $a l^{16}$ conducted a systematic review to evaluate the effectiveness of online social networks on behaviour change interventions targeting a range of modifiable health behaviours such as tobacco use, alcohol consumption, dietary intake and physical activity. A systematic review by Willis $e t a l^{17}$ explored the use of social networks as a primary intervention platform by evaluating the effectiveness of weight management interventions delivered through such platforms. Klassen et al ${ }^{18}$ conducted a mixed-methods systematic review to investigate the use of social media for nutrition outcomes among youth.
Another issue where digital technology has been particularly noticeable is food marketing. Whereas most research on food marketing still focuses on traditional broadcast media, there has been some momentum towards researching digital food marketing in recent years. This includes a systematic review on digital marketing and youth attitudes and behaviour related to unhealthy commodities (food, alcohol and tobacco) by Buchanan et $\mathrm{l}^{19}$ and reports by the WHO. ${ }^{20} 21$

In summary, these reviews and reports, along with individual studies, have identified the potential of digital technology for health promotion interventions, through dietary and physical activity mobile apps for selfmonitoring, among others. ${ }^{22}$ At the same time, the existing literature also indicates the potential harm offered by the digital world to nutritional health, for example, via increased consumption of unhealthy snacks due to influencer digital food marketing, ${ }^{23}$ or the increase in particular social behaviours online linked to rising body image and eating disorders. ${ }^{24}$

In the context of the widespread use of such technologies in late modernity and the consequent shift towards a digital society, it has been suggested that the sum of

Table 2 Inclusion and exclusion criteria for the scoping review

\section{Inclusion criteria}

- Peer-reviewed articles, including original research and review articles

- Commentaries and opinion pieces published in peerreviewed journals

- Conference proceedings, dissertations/theses and abstracts published in peer-reviewed journals

- Protocols

- Indexed in MEDLINE, EMBASE, Scopus or Web of Science

- Published from year 2000 onwards

- Language: English

\section{Exclusion criteria}

- Books and book chapters

- Book reviews

- Grey literature

- Website and newspaper articles

- Social media content

- Studies using digital research methods but not about digital technology and nutritional health/food environments Studies on digital public health, including interventions, but not related to the one of the eight dimensions of the food environment 
Table 3 Search strategy for Medline

\section{\# Search syntax}

\section{Digital Technology}

\section{1 internet/}

2 exp Webcasts/

3 exp Web Browser/

4 exp Video Games/

5 exp Virtual Reality/

6 exp Social Media/

7 exp Smartphone/

8 exp Online Social Networking/

9 exp Mobile Applications/

10 exp Electronic Mail/

11 exp Data Visualization/

12 exp "Cell Phone Use"/

13 exp Cell Phone/

14 exp Blogging/

15 exp Attitude to Computers/

16 (blog* or microblog $\left.{ }^{\star}\right) \cdot a b, k w, t i$.

17 (cyber $^{*}$ or virtual or digital $\left.{ }^{*}\right)$.ab,kw,ti.

18 ((digital or new) adj media).ab,kw,ti.

19 "information technolog*".ab,kw,ti.

20 (smartphone* or mobile* or touchscreen* or wearable ${ }^{\star}$ ) ab,kw,ti.

21 (social adj (media or network*)).ab,kw,ti.

22 (web-based or online or on-line).ab,kw,ti.

23 (website* or web site* or webpage* or web page ${ }^{\star}$ ). ab,kw,ti.

24 (Facebook or Instagram* or Twitter or tweet* or Snapchat or YouTube or Reddit or WhatsApp or TikTok or Tumblr or Pinterest or Linkedln).ab,kw,ti.

251 or 2 or 3 or 4 or 5 or 6 or 7 or 8 or 9 or 10 or 11 or 12 or 13 or 14 or 15 or 16 or 17 or 18 or 19 or 20 or 21 or 22 or 23 or 24

\section{Food Environments}

26 ((food or nutrition* or eating or obesogenic) adj environment $\left.{ }^{\star}\right) \cdot a b, k w, t i$.

27 (food adj (desert* or swamp*)).ab,kw,ti.

28 (food adj1 (accept $^{\star}$ or access ${ }^{\star}$ or acqui* or ad or ads or advertis $^{*}$ or aesthetic* or afford* or attitude* or availab* or brand ${ }^{\star}$ or choice ${ }^{\star}$ or composition or consumption or convenience or cost* or cultur ${ }^{\star}$ or desir ${ }^{\star}$ or knowledge ${ }^{\star}$ or label ${ }^{\star}$ or marketing or outlet* or packag* or perception* or practice $^{\star}$ or preference* or prepar* or price $^{\star}$ or pricing ${ }^{\star}$ or process ${ }^{\star}$ or promot ${ }^{\star}$ or provision* or purchas* or quality or retail or sale* or selection or service $^{\star}$ or shop* or sponsorship* or stall* or store* or tast $^{\star}$ or vendor $\left.\left.{ }^{\star}\right)\right) \cdot a b, k w$,ti.

29 (food porn or foodporn or gastroporn).ab,kw,ti.

30 "foodscape*".ab,kw,ti.

Continued
Table 3 Continued

\section{\# Search syntax}

31 (cafe $^{\star}$ or canteen ${ }^{*}$ or restaurant ${ }^{*}$ or supermarket ${ }^{\star}$ or takeaway* or take-away or vending machine* or kiosk $\left.^{\star}\right) \cdot a b, k w$,ti.

32 (grocery adj (shop* or store*)).ab,kw,ti.

3326 or 27 or 28 or 29 or 30 or 31 or 32

3425 and 33

35 limit 34 to english language

36 limit 35 to $y r=$ "2000-Current"

digital influences on health and nutrition goes beyond social media, digital health promotion interventions and digital food marketing, to include a broad range of digital actors and activities that are creating a new layer to food environments, the digital food environment. ${ }^{13}$ While the literature is abundant on studies linking food, nutrition and digital technology, an attempt to conceptualise the digital food environment is new. This proposed scoping review intends to contribute to that process, as the first stage in a larger ongoing research project. ${ }^{25}$

The aim of this planned scoping review is therefore to map and collate the published academic literature on the digital food environment. The findings will be used to support the development of a definition and conceptual framework of the digital food environment, characterise its components and identify potential consequences for diets and nutritional health.

Specific objectives are as follows:

- Develop a descriptive overview of existing academic literature to uncover research trends on aspects related to the digital food environment.

- Provide elements to help characterise the digital food environment and develop this concept.

- Contribute to the development of a conceptual framework for digital food environments.

- Make recommendations and identify research gaps.

\section{METHODS AND ANALYSIS}

Scoping reviews allow for the exploration of broad research questions. They are useful when a systematic mapping of the available evidence is required that indicates the scope and coverage of current literature (including main concepts, theories and knowledge gaps), rather than providing detailed answers to very specific questions. ${ }^{26-28}$ This proposed scoping review will involve a mapping of previous studies to determine the status of knowledge on the digital food environment. It aims to provide an overview of this broad study field, and will prioritise breadth over depth, ${ }^{29}$ not searching for exhaustiveness and completeness, but rather for a comprehensive overview of the available evidence. ${ }^{30}$ It will identify the breadth of research on themes related to the digital food environment, focusing on the range of studies that 


\section{Table 4 Preliminary charting table \\ Description (including examples of categories, which will be expanded as \\ Item themes emerge)}

\begin{tabular}{|c|c|}
\hline Author(s) & \\
\hline Title & \\
\hline Year of publication & \\
\hline Journal & \\
\hline $\begin{array}{l}\text { Country/geographical } \\
\text { area }\end{array}$ & $\begin{array}{l}\text { By country } \\
\text { By geographical area (continents) } \\
\text { By income category (high-income, } \\
\text { middle-income and low-income } \\
\text { countries) } \\
\ldots\end{array}$ \\
\hline Study type & $\begin{array}{l}\text { Original research } \\
\text { Systematic review } \\
\text { Commentary } \\
\text { Protocol } \\
\ldots\end{array}$ \\
\hline $\begin{array}{l}\text { Aims/objectives of the } \\
\text { study }\end{array}$ & $\begin{array}{l}\text { Describe the stated objective of the } \\
\text { publication }\end{array}$ \\
\hline Study population & $\begin{array}{l}\text { Women } \\
\text { Men } \\
\text { Children } \\
\text { Adolescents } \\
\text { Elderly } \\
\ldots\end{array}$ \\
\hline Methods & $\begin{array}{l}\text { RCTs* } \\
\text { Case studies } \\
\text { Social network analysis } \\
\ldots\end{array}$ \\
\hline Themes & $\begin{array}{l}\text { Digital health and nutrition literacy } \\
\text { Innovation on digital food services (eg, } \\
\text { online food retail) } \\
\text { Digital social engagement on nutrition } \\
\text { Internet food subcultures } \\
\text { Social media consequences on nutrition } \\
\ldots\end{array}$ \\
\hline $\begin{array}{l}\text { Food environment } \\
\text { dimensions }\end{array}$ & $\begin{array}{l}\text { Food availability } \\
\text { Food prices } \\
\text { Vendor and product properties } \\
\text { Food marketing } \\
\text { Food accessibility } \\
\text { Food affordability } \\
\text { Convenience } \\
\text { Desirability }\end{array}$ \\
\hline $\begin{array}{l}\text { Health and nutrition } \\
\text { outcomes }\end{array}$ & $\begin{array}{l}\text { Describe the reported outcomes (for } \\
\text { intervention studies) }\end{array}$ \\
\hline Other outcomes & Describe the reported outcomes \\
\hline Settings & $\begin{array}{l}\text { Social networking services } \\
\text { Websites } \\
\text { Online communities } \\
\text { Games } \\
\ldots\end{array}$ \\
\hline
\end{tabular}

${ }^{*} \mathrm{RCTs}$, randomised controlled trials.

are available and the identification of gaps, rather than focusing on one specific theme in depth.

The planning of this scoping review has been informed by the methodological framework for scoping reviews proposed by Arksey and O'Malley ${ }^{31}$ and further developed by Levac et al. ${ }^{32}$ Development and reporting will follow the Preferred Reporting Items for Systematic Reviews and Meta-Analyses-Extension for Scoping Reviews (PRISMA-ScR) checklist and guidelines, ${ }^{27}$ which have also been consulted for the development of this protocol.

While focusing on breadth over depth may be a limitation of this study, this scoping review may be the gateway to future systematic reviews for in-depth exploration of particular/specific topics identified through this study. It will also inform the next stages in the broader research project previously mentioned. ${ }^{25}$

\section{Conceptual framework}

Currently, no definition of the digital food environment exists. This proposed scoping review aims to inform the development of such a definition and conceptual framework. In order to do so, it will be guided by the food environments conceptual framework developed by Turner $e t$ $a l l^{5}$ adding a digital dimension. While other frameworks on food environments exist, this one in particular was chosen as it is one of the most recent, and was developed based on a comprehensive review of the literature on food environments.

According to this framework, a food environment is part of the broader food system (from farm to flush) and includes two domains: an external domain and a personal domain. There are four dimensions to the external domain:

1. Food availability.

2. Food prices.

3. Food vendor and product properties (which includes issues such as food quality, composition, level of processing, packaging, among others).

4. Food marketing and regulation.

In the personal domain, there are four additional dimensions:

5. Food accessibility.

6. Food affordability.

7. Convenience (for preparing, cooking and consuming food).

8. Desirability (preferences, acceptability, tastes, desires, attitudes, culture, knowledge and skills).

These eight dimensions will inform the development of the search strategy, as they will guide the choice of search terms to find relevant studies on the food environment. These will be combined with search terms relating to digital technology. For the purpose of this scoping review, digital technologies include a broad range of electronic tools, systems and devices, such as social media and other forms of new media, smartphone/mobile applications, digital games, artificial intelligence, blockchain, blogs, wearable devices, virtual reality, among others.

\section{Research questions}

The research questions that will guide the scoping review are presented in table 1 . 


\section{Inclusion and exclusion criteria}

This proposed scoping review will include publications from year 2000 onwards, to coincide with the spread in use of digital technology by the general population and the emergence of social media. ${ }^{18}$ The first social network, SixDegrees, was launched in 1997; the first scientific literature on blogs appeared in 2003, with research on other forms of social media emerging after that. ${ }^{33}$ Other studies have chosen similar cut-off dates. ${ }^{18}{ }^{34}$ No geographical or population restrictions will be applied, given the desired breadth of the review. Other criteria for inclusion or exclusion are outlined in table 2. These will be refined post hoc for relevance, through an iterative process to take place once abstracts have been identified and screened, as typical of scoping reviews. ${ }^{31} 32$

\section{Search strategy}

The search strategy was developed in consultation with a senior librarian. It will cover terms related to two main concepts related to the digital food environment: digital technology and food environment. As the concept of digital food environment is new and under elaboration, having no formal definition or consensus on descriptive words, terminology used to describe aspects related to it is likely to be inconsistent, varied and general. The definition of search terms has endeavoured to capture that broad scope, and the conceptual framework described above has been a useful tool in this regard.

Search terms were defined using an interactive scanning of the literature, as described by Booth, ${ }^{35}$ aiming to increase the likelihood of retrieving material relevant to the research questions. Table 3 presents the search terms to be used in the scoping review. The search strategy will include free text and subject heading terms, which will be adapted to each of the databases.

The search will be conducted in the following databases: MEDLINE (OVID interface, 1948 onwards) and EMBASE (OVID interface, 1974 onwards), two major databases on health sciences and life sciences; and Scopus (Elsevier) and Web of Science (Clarivate Analytics), two major multidisciplinary databases, to cover the non-clinical aspects of the relationship between humans, digital technology and food, including cultural aspects, for example. Citation searching will also be applied to identify additional key studies that may not be indexed in the databases searched. ${ }^{30}$ By using this technique, reference lists of existing primary studies and reviews will be checked to ensure the relevant literature appearing in such reviews is taken into account in this study.

\section{Study selection}

One researcher will carry out the search through electronic databases and keep a record of searches. The software Endnote V.X9 (Clarivate Analytics) will be used for database organisation of the results retrieved. Duplicate removal and screening will be conducted using the online software Covidence (Veritas Health Innovation). Four researchers will be involved in the screening of titles and abstracts against the inclusion and exclusion criteria. Following a model previously applied in other reviews, ${ }^{36} 37$ at a first stage the researchers will independently screen a sample of the results to determine the degree of consistency in the individual assessments. Once an acceptable degree of consistency has been reached, the remaining articles will be screened (title and abstract) by one of the researchers. At a second stage of screening (full text), two reviewers will work independently. One researcher will screen all records, while the work of the second reviewer will be divided equally among three researchers. A third reviewer may be involved when agreement cannot be reached by the two main reviewers.

\section{Data extraction and analysis}

Data extraction (charting) will be conducted using standardised tools to be developed for this scoping review. A preliminary charting table with indicators to be used to address the research questions is provided in table 4 . The charting table will be piloted by two reviewers on a sample of included studies to adjust its sensitivity. One reviewer will then perform the analysis, and the second reviewer will independently check a sample of the total of articles, for accuracy. Any disagreements will be resolved through the involvement of a third reviewer.

The data extracted in the standardised tool will be summarised through thematic content analysis, ${ }^{38}$ grouping findings in similar categories based on commonalities. It will also be analysed to identify historical trends and the main research areas/topics that are being researched and published. Given the scope and aims of this review, it will include both large-scale and small-scale studies and a combination of different study designs and methods (including qualitative and quantitative data). This is not uncommon for scoping reviews. ${ }^{39}$

\section{Patient and public involvement}

No patients involved. As the study is a literature review, there are no study participants.

\section{Ethics and dissemination}

This study is based on the analysis of published scientific literature and does not involve patients, medical research or any type of personal information. Thus, no ethical approval is required. The results of this scoping review will be submitted for publication in an international peerreviewed journal (preferably open access) and scientific meetings and conferences on public health, nutrition and digital research. Once published, results will be disseminated through digital science communication platforms, including academic social media, to amplify its reach and usefulness.

\section{Twitter Sabrina Ionata Granheim @sabrinaionata}

Contributors SIG conceived the scoping review, developed the research questions and drafted the manuscript. EO supported the development of the search strategy as a whole and the detailed search syntax, and reviewed the manuscript. MT, LT and LET supported the conceptualisation of the study, critically reviewed drafts and edited the manuscript. 
Funding This scoping review received no specific grant from any funding agency in the public, commercial or not-for-profit sectors. It is funded by the Inland Norway University of Applied Sciences as part of the PhD project of SIG, supervised by MT, LET and LT.

Competing interests None declared.

Patient consent for publication Not required.

Provenance and peer review Not commissioned; externally peer reviewed.

Open access This is an open access article distributed in accordance with the Creative Commons Attribution Non Commercial (CC BY-NC 4.0) license, which permits others to distribute, remix, adapt, build upon this work non-commercially, and license their derivative works on different terms, provided the original work is properly cited, appropriate credit is given, any changes made indicated, and the use is non-commercial. See: http://creativecommons.org/licenses/by-nc/4.0/.

\section{ORCID iD}

Sabrina Ionata Granheim http://orcid.org/0000-0003-4326-1772

\section{REFERENCES}

1 Glanz K, Sallis JF, Saelens BE, et al. Healthy nutrition environments: concepts and measures. Am J Health Promot 2005;19:330-3.

2 Swinburn B, Sacks G, Vandevijvere S, et al. INFORMAS (international network for food and Obesity/non-communicable diseases research, monitoring and action support): overview and key principles. Obes Rev 2013;14 Suppl 1:1-12.

3 Herforth A, Ahmed S. The food environment, its effects on dietary consumption, and potential for measurement within agriculturenutrition interventions. Food Secur 2015;7:505-20.

4 HLPE. Nutrition and food systems. Rome: High Level Panel of Experts on Food Security and Nutrition of the Committee on World Food Security, 2017.

5 Turner C, Aggarwal A, Walls $\mathrm{H}$, et al. Concepts and critical perspectives for food environment research: a global framework with implications for action in low- and middle-income countries. Global Food Security 2018:18:93-101.

6 Swinburn BA, Kraak VI, Allender S, et al. The global Syndemic of obesity, undernutrition, and climate change: the Lancet Commission report. Lancet 2019;393:791-846.

7 Lytle LA, Sokol RL. Measures of the food environment: a systematic review of the field, 2007-2015. Health Place 2017;44:18-34.

8 Engler-Stringer R, Le H, Gerrard A, et al. The community and consumer food environment and children's diet: a systematic review. BMC Public Health 2014;14:522.

9 Gamba RJ, Schuchter J, Rutt C, et al. Measuring the food environment and its effects on obesity in the United States: a systematic review of methods and results. $J$ Community Health 2015;40:464-75.

10 Gustafson A, Hankins S, Jilcott S. Measures of the consumer food store environment: a systematic review of the evidence 2000-2011. Community Health 2012;37:897-911.

11 Feng J, Glass TA, Curriero FC, et al. The built environment and obesity: a systematic review of the epidemiologic evidence. Health Place 2010;16:175-90.

12 Galbraith-Emami S, Lobstein T. The impact of initiatives to limit the advertising of food and beverage products to children: a systematic review. Obes Rev 2013;14:960-74.

13 Granheim SI. The digital food environment. UNSCN Nutrition 2019;44:115-21.

14 Gruzd A. Current State of Social Media Research: From Practice to Theory \#SMSociety 15 Toronto: Social Media Lab, Ryerson University, 2015. Available: https://socialmedialab.ca/2015/08/05/current-stateof-social-media-research-from-practice-to-theory-part-1/ [Accessed 07 Oct 2019].

15 Williams G, Hamm MP, Shulhan J, et al. Social media interventions for diet and exercise behaviours: a systematic review and metaanalysis of randomised controlled trials. BMJ Open 2014;4:e003926.
16 Maher CA, Lewis LK, Ferrar K, et al. Are health behavior change interventions that use online social networks effective? A systematic review. J Med Internet Res 2014;16:e40.

17 Willis EA, Szabo-Reed AN, Ptomey LT, et al. Do weight management interventions delivered by online social networks effectively improve body weight, body composition, and chronic disease risk factors? A systematic review. J Telemed Telecare 2017:23:263-72.

18 Klassen KM, Douglass $\mathrm{CH}$, Brennan L, et al. Social media use for nutrition outcomes in young adults: a mixed-methods systematic review. Int J Behav Nutr Phys Act 2018;15:70.

19 Buchanan L, Kelly B, Yeatman H, et al. The effects of digital marketing of unhealthy commodities on young people: a systematic review. Nutrients 2018;10. doi:10.3390/nu10020148. [Epub ahead of print: 29 Jan 2018].

20 WHO. Tackling food marketing to children in a digital world: transdisciplinary perspectives. Copenhagen: World Health Organization Regional Office for Europe, 2016.

21 WHO. Monitoring and restricting digital marketing of unhealthy products to children and adolescents. Moscow: WHO European Office for the Prevention and Control of Noncommunicable Diseases (NCD Office), 2019.

22 Fakih El Khoury C, Karavetian M, Halfens RJG, et al. The effects of dietary mobile Apps on nutritional outcomes in adults with chronic diseases: a systematic review and meta-analysis. J Acad Nutr Diet 2019;119:626-51.

23 Coates AE, Hardman CA, Halford JCG, et al. Social media Influencer marketing and children's food intake: a randomized trial. Pediatrics 2019;143. doi:10.1542/peds.2018-2554. [Epub ahead of print: 04 Mar 2019].

24 Fardouly J, Vartanian LR. Social media and body image concerns: current research and future directions. Current Opinion in Psychology 2016;9:1-5.

25 Høgskolen i Innlandet. Digital food environments and their influence on the nutritional health of young women in Norway, 2019. Available: https://app.cristin.no/projects/show.jsf?id=638584 [Accessed 07/10/2019].

26 Munn Z, Peters MDJ, Stern C, et al. Systematic review or scoping review? guidance for authors when choosing between a systematic or scoping review approach. BMC Med Res Methodol 2018;18.

27 Tricco AC, Lillie E, Zarin W, et al. PRISMA extension for scoping reviews (PRISMA-ScR): checklist and explanation. Ann Intern Med 2018;169:467-+.

28 Moher D, Stewart L, Shekelle P. All in the family: systematic reviews, rapid reviews, scoping reviews, realist reviews, and more. Syst Rev 2015;4:183.

29 Shemilt I, Simon A, Hollands GJ, et al. Pinpointing needles in giant haystacks: use of text mining to reduce impractical screening workload in extremely large scoping reviews. Res Synth Methods 2014;5:31-49.

30 Levay P, Craven J. Systematic searching : practical ideas for improving results. London: Facet Publishing, 2019.

31 Arksey H, O'Malley L. Scoping studies: towards a methodological framework. Int J Soc Res Methodol 2005;8:19-32.

32 Levac D, Colquhoun H, O'Brien KK. Scoping studies: advancing the methodology. Implement Sci 2010;5:69.

33 Taylor J, Pagliari C. Comprehensive scoping review of health research using social media data. BMJ Open 2018;8:e022931.

34 Snelson CL. Qualitative and mixed methods social media research: a review of the literature. International Journal of Qualitative Methods 2016;15.

35 Booth A. Unpacking your literature search toolbox: on search styles and tactics. Health Info Libr J 2008;25:313-7.

36 Winpenny EM, Penney TL, Corder K, et al. Change in diet in the period from adolescence to early adulthood: a systematic scoping review of longitudinal studies. Int J Behav Nutr Phys Act 2017;14:60.

37 Raanaas RK, Bjøntegaard H. Ø., Shaw L. A scoping review of participatory action research to promote mental health and resilience in youth and adolescents. Adolescent Research Review 2018;26.

38 Aveyard H. Doing a literature review in health and social care: a practical guide. 4th edn. London: Open University Press/ McGrawHill Education, 2019.

39 Armstrong R, Hall BJ, Doyle J, et al. Cochrane Update. 'Scoping the scope' of a cochrane review. J Public Health 2011;33:147-50. 